\title{
Maturation of Synaptic Transmission at End-Bulb Synapses of the Cochlear Nucleus
}

\author{
Stephan Brenowitz ${ }^{1,2}$ and Laurence O. Trussell ${ }^{2}$ \\ ${ }^{1}$ Neuroscience Training Program, University of Wisconsin, Madison, Wisconsin 53706, and ${ }^{2}$ Oregon Hearing Research \\ Center and Vollum Institute, Oregon Health Sciences University, Portland, Oregon 97201
}

\begin{abstract}
Neurons of the avian nucleus magnocellularis transmit phaselocked action potentials of the auditory nerve in a pathway that contributes to sound localization based on interaural timing differences. We studied developmental changes in synaptic transmission that enable the end-bulb synapse to function as a synaptic relay. In chick, although the auditory system begins to function early in embryonic development, maturation of audition around the time of hatching suggested that synaptic transmission in the cochlear nucleus of young chicks may undergo further developmental changes. Synaptic physiology was investigated via patch-clamp recordings from bushy cells in brainstem slices during stimulation of auditory nerve fibers at $35^{\circ} \mathrm{C}$. Compared with embryonic synapses (embryonic day 18 ), post-hatch chicks (post-hatch days 1-11) exhibited high prob-
\end{abstract}

Localization of sound based on differences in phase or arrival time of sounds at the two ears requires accurate preservation of timing information by neurons of the auditory system. In the chick, such temporal resolution necessitates accurate and reliable transmission of auditory nerve activity by the end-bulb synapse in the cochlear nucleus magnocellularis (nMag). Preservation of timing information by specialized auditory synapses results from physiological and anatomical specializations (Oertel, 1999; Trussell, 1999). In the chick, such features appear early in development. Initial formation of the nMag end-bulb synapse occurs by embryonic day (E) 11 when responses in nMag neurons to auditory nerve stimulation (Jackson et al., 1982) or sound (Saunders et al., 1973) first arise. Retraction of dendrites (Jhaveri and Morest, 1982), synapse elimination (Jackson and Parks, 1982), and maturation of end-bulb morphology (Jhaveri and Morest, 1982; Rubel and Parks, 1988) appear complete by E18. Tuning properties of auditory nerve fibers achieve mature values before hatching (Rebillard and Rubel, 1981; Manley et al., 1991). EPSCs in nMag at late embryonic stages have large amplitudes and rapid kinetics but also exhibit strong synaptic depression during stimulation at frequencies expected of the auditory nerve in vivo. Such EPSPs fall subthreshold after several stimuli at frequencies of 200 $\mathrm{Hz}$ (Brenowitz et al., 1998). Although activation of presynaptic $\mathrm{GABA}_{\mathrm{B}}$ receptors on auditory nerve terminals improved reliabil-

\footnotetext{
Received July 16, 2001; revised Sept. 17, 2001; accepted Sept. 18, 2001.

This work was supported by National Institutes of Health Grants DC02004, NS28901, and GM07507. We thank Drs. G. Awatramani, E. Chapman, R. Fettiplace, D. Oertel, T. Otis, R. Pearce, and H. von Gersdorff for helpful comments and discussion.

Correspondence should be addressed to Laurence O. Trussell, Auditory Neuroscience L-335A, Oregon Health Sciences University, 3181 SW Sam Jackson Park Road, Portland OR, 97201. E-mail: trussell@ohsu.edu.

Copyright (C) 2001 Society for Neuroscience $0270-6474 / 01 / 219487-12 \$ 15.00 / 0$
}

ability of firing a well timed postsynaptic action potential during high-frequency stimulation of the auditory nerve. Improvements in reliability and timing of postsynaptic spikes were accompanied by a developmental increase in steady-state EPSCs during stimulus trains and a decline in the extent of synaptic depression. Synchrony of EPSCs during stimulus trains improved with age. An increased pool of synaptic vesicles, lower release probability, larger and faster transmitter quanta, and reduced AMPA receptor desensitization contributed to these changes. Together, these factors improve the ability of cochlear nucleus magnocellularis neurons to faithfully transmit timing information encoded by the auditory nerve.

Key words: short-term depression; AMPA receptors; cochlear nucleus; end-bulb synapse; auditory; development ity of signaling during short bursts of activity, the probability of spike firing after the 10th stimulus of a $200 \mathrm{~Hz}$ train remained low $(<50 \%)$.

Such findings in embryos, however, are not consistent with in vivo recordings from older animals that indicate sustained activity at higher rates. In post-hatch day 10-28 (P10-28) chicks, in vivo firing rates of nMag neurons caused by spontaneous auditory nerve activity alone were $31-231 \mathrm{~Hz}$ and increased to $110-480$ $\mathrm{Hz}$ with acoustic stimulation (Warchol and Dallos, 1990). Improvements in high-frequency responses in auditory neurons between P4 and P14 have also been reported in rat and mouse medial nucleus of the trapezoid body (MNTB) (Chuhma and Ohmori, 1998; Taschenberger and von Gersdorff, 2000; Futai et al., 2001) and mouse cochlear nucleus (Wu and Oertel, 1987). Thus, it might be expected that reliability of signal transfer at the nMag end-bulb synapse improves significantly after hatching.

Developmental changes in patterns and levels of activity in the auditory system further predict that maturation of transmission in nMag occurs around the time of hatching. Sound-evoked response thresholds in the auditory nerve and cochlear nucleus decline and reach adult values between E19 and P1, resulting from clearance of middle ear fluids and improved transduction by the cochlea (Saunders et al., 1973; Rebillard and Rubel, 1981). Behavioral studies indicate a decline in auditory thresholds between hatching and P4 (Gray and Rubel, 1985). Patterns of spontaneous auditory nerve firing change around E19, when rhythmic bursts of action potentials are replaced by the sustained Poisson-like firing observed in adults (Lippe, 1994; Jones and Jones, 2000). Spontaneous activity is thought to play an important role in synaptic modification during development of sensory systems (Katz and Shatz, 1996). Thus, increased spontaneous and sound-evoked auditory nerve activity occurring around the time 
A

Figure 1. Improved suprathreshold transmission in post-hatch synapses. $A$, Trains of 20 stimuli delivered at 200 $\mathrm{Hz}$ to an E18 (left trace) and a P4 synapse (right trace). At $200 \mathrm{~Hz}$, action potential failures were not observed in P4 synapses. $B$, Action potentials were defined as responses showing an inflection (arrow, top traces) that was determined by the presence of a biphasic rise in the differentiated trace (arrow, bottom traces). $C$, Probabilities of action potential firing during stimulus trains was measured as the fraction of suprathreshold EPSPs for each stimulus during 10 repetitions delivered at $30 \mathrm{sec}$ intervals. Data shown are for P2-4 synapses (circles; $n=6$ neurons) and E18 synapses (squares; $n=4-7$ neurons).

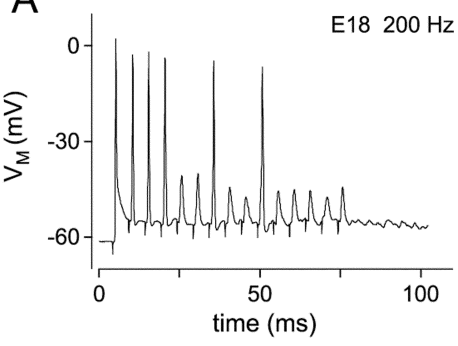

C

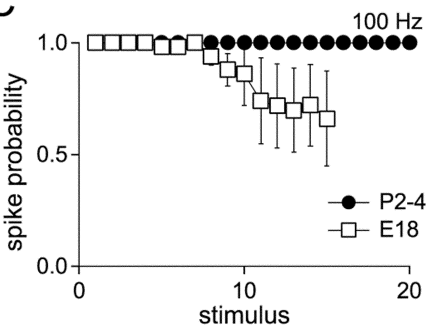

B

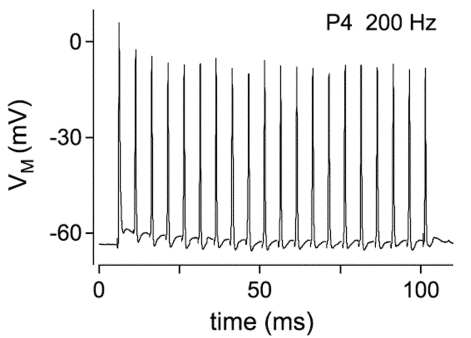

of hatching may be a driving force for further maturation of synaptic function in nMag.

In this study, by comparing transmission in late embryos (E18) and young hatchlings (P1 through P11), we examined developmental changes in transmission at a morphologically mature synapse that is experiencing increased activity levels. During this time, synapses exhibited marked improvements in their ability to reliably generate well timed postsynaptic action potentials during trains of high-frequency auditory nerve stimulation. Experiments were conducted to determine the mechanisms underlying this developmental transition.

\section{MATERIALS AND METHODS}

Physiology. Brainstem slices $(250-300 \mu \mathrm{m})$ were prepared from E18 and P1-11 chicks. Dissections were performed in ice-cold oxygenated saline containing (in mM): $140 \mathrm{NaCl}, 20$ glucose, $10 \mathrm{HEPES}, 5 \mathrm{KCl}, 3 \mathrm{CaCl}_{2}$, $1 \mathrm{MgCl}_{2}, \mathrm{pH} 7.35$. Slices were then maintained at $34^{\circ} \mathrm{C}$ for $30 \mathrm{~min}$. During recordings $\left(34-36^{\circ} \mathrm{C}\right)$ slices were perfused at $2-4 \mathrm{ml} / \mathrm{min}$ in a 1 $\mathrm{ml}$ chamber. Neurons were viewed with a Zeiss Axioskop and Olympus $60 \times$ water immersion lens using differential interference contrast optics and infrared illumination. For measurement of AMPA-mediated EPSCs, saline was supplemented with (in $\mu \mathrm{M}$ ): 100 DL-2-amino-5phosphonovalerate (APV), 10 7-Cl-kynurenate, 10 SR-95531, and 2 strychnine. In some experiments, GYKI-52466 $(20 \mu \mathrm{M})$, a noncompetitive AMPA receptor antagonist, was added to bath solutions to reduce EPSC conductance. Neurons were voltage clamped with an Axopatch 200B amplifier (Axon Instruments, Foster City, CA) at $-30 \mathrm{mV}$ (for recording AMPA receptor-mediated EPSCs) or $-60 \mathrm{mV}$ [for recording miniature EPSCs (mEPSCs)]. Electrode series resistance (2-8 M $\Omega$ ) was compensated $80-95 \%$. Pipettes were filled with an intracellular solution containing (in mM): 125 Cs-methanesulfonate, $15 \mathrm{CsCl}, 10 \mathrm{HEPES}, 5$ BAPTA, $1 \mathrm{MgCl}_{2}$, $\mathrm{pH}$ 7.25. During current-clamp experiments, pipettes contained (in mM): $140 \mathrm{~K}$-gluconate, $5 \mathrm{NaCl}, 1 \mathrm{MgCl}_{2}, 10 \mathrm{HEPES}, 1$ EGTA, pH 7.3. Synaptic responses were obtained by positioning a stimulus electrode $(1.5-3 \mathrm{M} \Omega$ ) onto nearby myelinated fibers $20-100 \mu \mathrm{m}$ from the postsynaptic cell body. Individual afferent auditory nerve axons were stimulated by $100-200 \mu \mathrm{sec}, 5-50 \mathrm{~V}$ pulses delivered via an isolated stimulus unit (AMPI Iso-flex). Currents were filtered at $5-10 \mathrm{kHz}$ and sampled at $20-50 \mathrm{kHz}$. Aniracetam stocks $(0.5 \mathrm{M}, 100 \times)$ were prepared in DMSO and added to extracellular solutions immediately before use. The final working concentration of aniracetam was $5 \mathrm{~mm}$, and aniracetam-containing solutions included 1\% (v/v) DMSO. For all experiments using aniracetam, control extracellular solutions were also supplemented with $1 \%$ DMSO. Means are reported as \pm SE. Chemicals and drugs were obtained from Sigma (St. Louis, MO), RBI (Natick, MA), and Tocris Cookson (Ballwin, MO).
To assess the quality of voltage clamp, the current-voltage relationship of EPSC amplitudes was measured at holding potentials ranging from -40 to $+20 \mathrm{mV}$. The relationship obtained was linear $(r=0.99 ; n=4$ neurons), suggesting minimal voltage error. However, bath application of $20 \mu \mathrm{M}$ GYKI-52466, a noncompetitive AMPA receptor antagonist, sufficient to block EPSC s by $64 \pm 2 \%(n=14)$, caused a small but consistent increase in paired-pulse depression, as expected if large EPSCs are limited by clamp error. The ratio of $\mathrm{EPSC}_{2} / \mathrm{EPSC}_{1}$ (with a $5 \mathrm{msec}$ interval) was $0.40 \pm 0.07$ and $0.36 \pm 0.06(n=6)$ in control and $20 \mu \mathrm{M}$ GYKI, respectively ( $p<0.05 ; t$ test). Although this effect was small, GYKI was added to bath solutions in some experiments to maximize voltage control.

Measurement of mEPSCs. Spontaneous mEPSCs were obtained at a holding potential of $-60 \mathrm{mV}$. Currents were filtered at $10 \mathrm{kHz}$ and sampled at $50 \mathrm{kHz}$. Events were detected using a template detection algorithm implemented in Axograph software (Axon Instruments).

\section{RESULTS}

\section{Action potentials during synaptic trains}

In embryos, depression at the nMag end-bulb synapse caused synaptic responses to become subthreshold during high-frequency trains (Brenowitz et al., 1998). To determine reliability of signal transfer in nMag in young hatchlings, we recorded EPSPs and action potentials in current-clamp configuration during stimulation of presynaptic auditory nerve fibers (Fig. $1 A$ ). The criterion for spike detection was the biphasic rising phase of a differentiated trace (Fig. $1 B$ ). In response to 100 and $200 \mathrm{~Hz}$ stimulation, neurons consistently fired spikes throughout stimulus trains of 20-40 stimuli. For P2-3 synapses, mean spike probability for stimuli 16-20 was 1.0, 1.0, and 0.81, at 100, 200, and $333 \mathrm{~Hz}$, respectively (Fig. 1C), compared with probabilities of $0.69,0.02$, and 0 for E18 synapses (Brenowitz et al., 1998). Thus, developmental changes occurring around the time of hatching greatly enhance reliability of signal transmission at the end-bulb synapse.

\section{Improvement in spike timing during trains}

Because temporally accurate transmission of auditory nerve activity by the cochlear nucleus is essential for detection of interaural timing differences used in sound localization, we compared temporal jitter in postsynaptic action potentials during stimulus trains in embryos and young hatchlings. Stimulus trains at $100 \mathrm{~Hz}$ were repeated 10 times at 20-30 sec intervals, and SDs of the time of action potential peaks were determined for each response of 
A

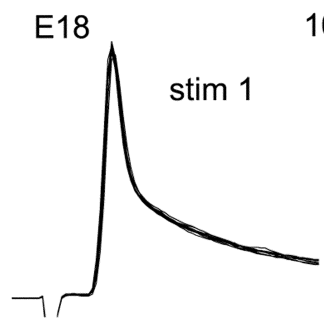

$100 \mathrm{~Hz}$
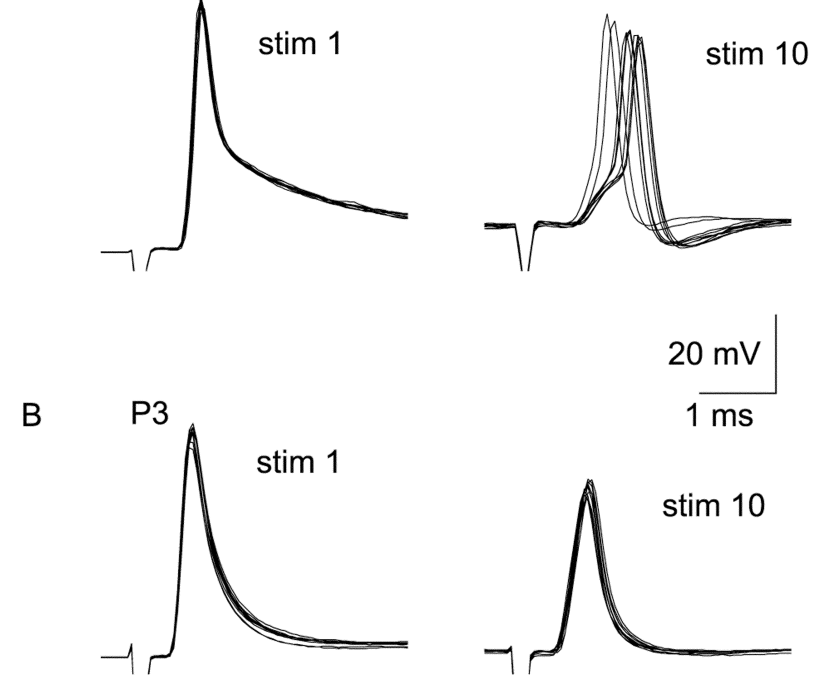

C

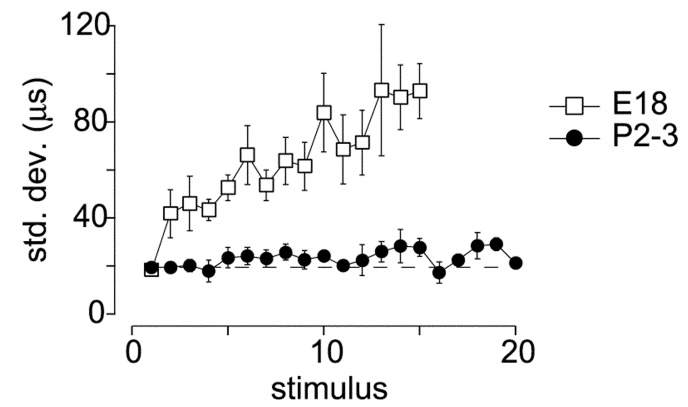

Figure 2. Improvement in action potential timing with older synapses. $A$, First and 10th responses are shown for 10 repetitions of a $100 \mathrm{~Hz}$ train in an E18 synapse. Action potentials show temporal jitter during the 10th stimulus. $B$, First and 10th responses for 10 repetitions of a $100 \mathrm{~Hz}$ train in a P3 synapse. Timing of action potentials during the 10th stimulus is improved. $C, \mathrm{SD}$ of peaks of action potentials were calculated for each stimulus of $100 \mathrm{~Hz}$ trains in E18 (squares; $n=9$ ) and P2-3 (circles; $n=5$ ) synapses. Progressive increase in variation of action potential timing seen in embryos is not present in $\mathrm{P} 2-3$ hatchlings.

the train. A frequency of $100 \mathrm{~Hz}$ was chosen so that action potentials were reliably generated in embryos (Brenowitz et al., 1998). Stimuli that produced subthreshold responses were not analyzed. Figure 2, $A$ and $B$, shows the 1st and 10th responses from an E18 and P3 synapse. The first response is well timed at both ages. During the train, depression of EPSPs in the E18 synapse causes variability in the time at which threshold is reached, producing jitter in the timing of the action potential (Chuhma and Ohmori, 1998; Taschenberger and von Gersdorff, 2000). In embryos, the SD in the time of the action potential peak increased from $18 \pm 3 \mu \mathrm{sec}$ for the first stimulus to $83 \pm 8 \mu \mathrm{sec}$ (average of last five stimuli of the train). In P2-3 synapses, temporal jitter increased from $19 \pm 2 \mu \mathrm{sec}$ on the first stimulus to $24 \pm 2 \mu \mathrm{sec}$ (average of last five action potentials) during $100 \mathrm{~Hz}$ stimulus trains. These values are similar to those reported by Golding et al. (1995), who reported temporal jitter of $20 \mu \mathrm{sec}$ in auditory nerve-evoked action potentials in octopus cells of mature mouse cochlear nucleus. These results indicate that changes in transmission at the end-bulb synapse around the time of hatching allow more accurate temporal coding of auditory nerve activity by the cochlear nucleus.

\section{Reduction in synaptic depression with age}

Further experiments were performed to examine the mechanisms that account for improvements in the reliability and temporal precision of high-frequency transmission. Under voltage clamp, transmission at the embryonic synapse in $\mathrm{nMag}$ is characterized by strong depression of synaptic currents (Zhang and Trussell, 1994a; Brenowitz et al., 1998). Therefore, we examined depression of EPSCs during stimulus trains at different ages. Trains of EPSCs were recorded during stimulation of single auditory nerve fibers at a holding potential of $-30 \mathrm{mV}$. Responses to $200 \mathrm{~Hz}$ stimulation in E18, P2, and P10 synapses are shown in Figure $3 A$. A progressive reduction in the amount of synaptic depression and an increase in steady-state EPSCs during trains are apparent during this developmental period. Average EPSC amplitudes during stimulus trains delivered at 100,200 , and $333 \mathrm{~Hz}$ are shown in Figure $3 B$. Trains of 20 stimuli were delivered in post-hatch synapses. Shorter trains of 10 stimuli were routinely delivered in embryonic synapses because greater depression made EPSC measurements unreliable during longer highfrequency trains. Data from post-hatch synapses were combined in two age groups of P2-3 and P6-11. At these three frequencies, average steady-state EPSC amplitudes $\left(\mathrm{EPSC}_{\mathrm{Ss}}\right.$; the average of the last three EPSCs in trains of 10 or 20 stimuli) showed progressive and significant increases in the age groups tested (ANOVA; $p<0.001$; Tukey post hoc comparison). For example, at $200 \mathrm{~Hz}, \mathrm{EPSC}_{\mathrm{SS}}$ was $0.52 \pm 0.02,2.53 \pm 0.02$, and $3.49 \pm 0.04$ $\mathrm{nA}$ at ages E18, P2-3, and P6-11, respectively (Fig. 3B). Between E18 and P6-11, EPSC $_{\text {SS }}$ increased 4.0-, 6.7-, and 6.8-fold at 100, 200, and $333 \mathrm{~Hz}$, respectively.

Synaptic depression was also examined after normalization of the initial EPSC amplitude of each train (Fig. 3C). Normalized depression declined progressively in the three age groups. Pairedpulse depression (PPD; $\mathrm{EPSC}_{2} / \mathrm{EPSC}_{1}$ ) with a $5 \mathrm{msec}$ interval changed from $0.25 \pm 0.03$ to $0.36 \pm 0.03$ to $0.61 \pm 0.06$ at ages E18, P2-3, and P6-11. The decline in synaptic depression was most apparent at the highest frequencies tested $(333 \mathrm{~Hz})$. Also, a slow phase of depression in E18 synapses that was apparent after two to three stimuli was reduced in older chicks (Fig. 3C, asterisk).

\section{Developmental changes in EPSC size and shape}

Amplitude and time course of EPSCs were compared in synapses from three age groups: E18, P2-3, and P6-11 (Fig. 4A,C). Between E18 and P2-3, EPSC amplitudes increased 68\%, from $8.4 \pm 0.9$ to $14.1 \pm 0.9 \mathrm{nA}(p<0.001 ;$ ANOVA; Tukey post hoc comparison). Mean EPSC amplitude for P6-11 synapses was $12.3 \pm 1.1 \mathrm{nA}$, not significantly different from for P2-3 synapses. Changes in EPSC time course are illustrated by scaling and superimposing EPSCs from synapses of different ages (Fig. 4B). Rise times (10-90\%) became faster between E18 and P2-3 but did not change significantly between P2-3 and P6-11. Fits of double-exponential functions to the decay phase of EPSCs indicated that the fast exponential component became faster by $50 \%$ between ages E18 and P6-11, causing a reduction of $41 \%$ in EPSC half-widths during this time (Fig. $4 B, C$ ). The observed increase in the overall amplitude of EPSCs therefore could explain part of the increase in synaptic strength during trains (Fig. 1) but cannot account for the dramatic reduction in synaptic depression with age (Fig. 3).

\section{Time course of EPSCs during trains}

Rapidly rising and decaying synaptic conductance serves an important function in nMag (Trussell, 1999). Brief EPSCs are 
A

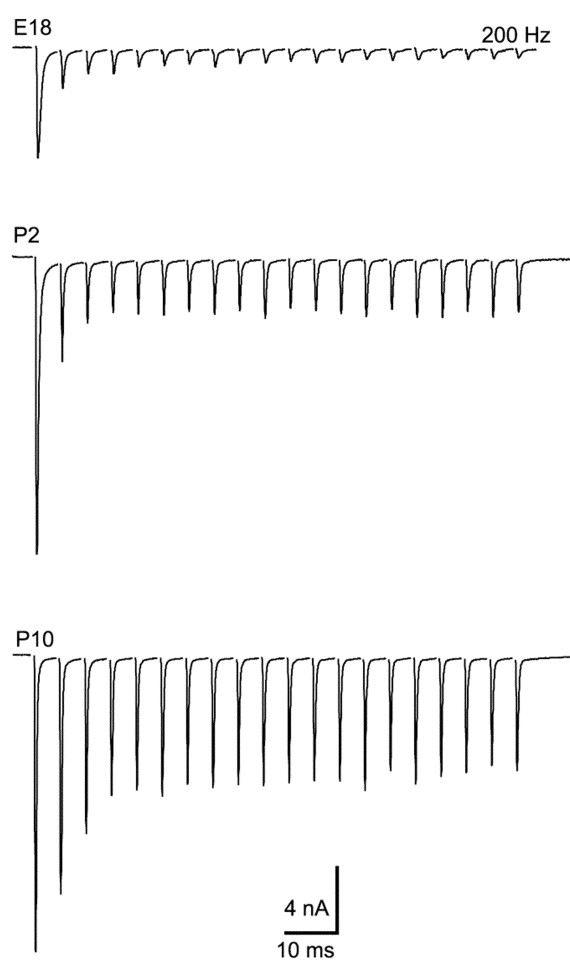

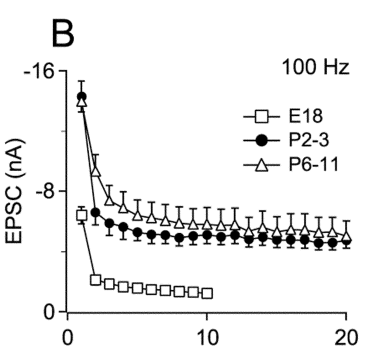

C
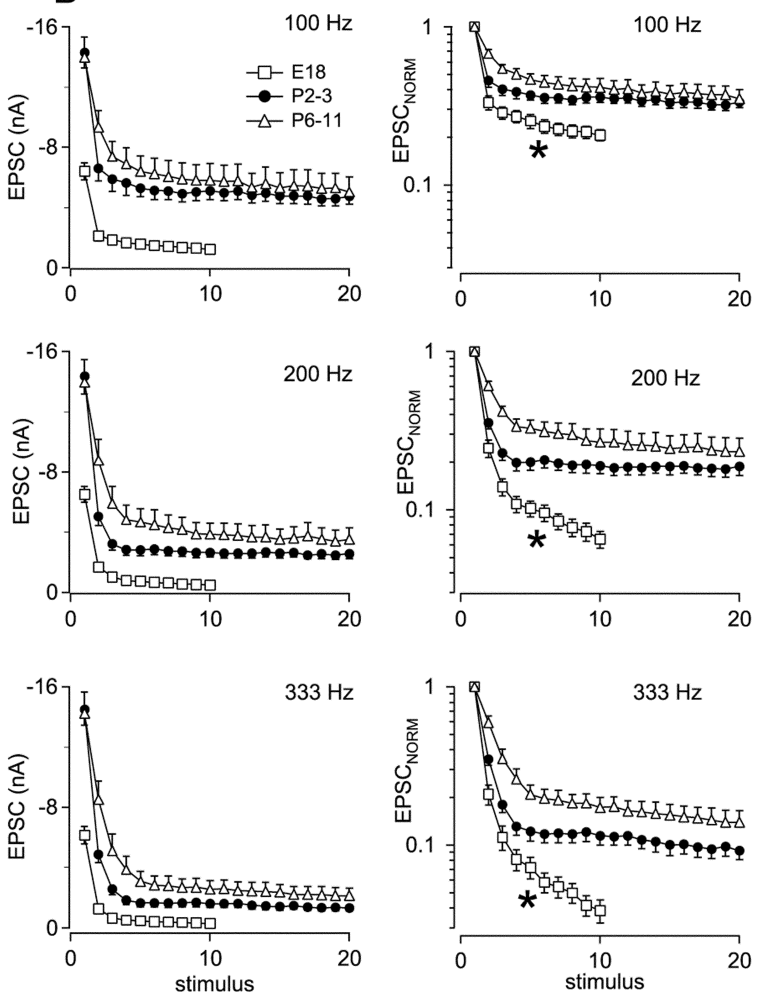

Figure 3. Reduction of synaptic depression during development. $A$, Trains of 20 EPSCs were evoked at $200 \mathrm{~Hz}$ in brain slices obtained from animals at different ages. Top trace, E18; middle trace, P2; bottom trace, P10. Averages of three to five traces are shown. $V_{\mathrm{m}}=-30 \mathrm{mV}$. B, Absolute amplitudes during $200 \mathrm{~Hz}$ stimulus trains. Trains of 10 and 20 stimuli were delivered to embryos and hatchlings, respectively. Summarized data from E18 $(n=12)$, P2-3 $(n=15)$, and P6-11 $(n=10)$ are shown. $C$, Depression during $200 \mathrm{~Hz}$ trains was compared by normalizing each EPSC to the first EPSC of each train. Data in $B$ and $C$ are from the same cells. Asterisks indicate a slow phase of depression present in embryos.

necessary for accurately timed postsynaptic action potentials that enable sound localization. Indeed, the presence of a lowthreshold potassium conductance makes rapidly rising synaptic conductance necessary for generation of spikes (Brew and Forsythe, 1995; Rathouz and Trussell, 1998). We therefore investigated developmental changes in time course of EPSCs during repetitive stimulation (Fig. 5). Rise times and half-widths of EPSCs were determined during $200 \mathrm{~Hz}$ trains at different ages (E18, P2-3, and P6-11). Rise times of EPSCs in E18 synapses increased progressively during 10 -stimulus trains by $66 \%$, from $0.20 \pm 0.01$ to $0.33 \pm 0.03 \mathrm{msec}($ Fig. $5 A$ ). In post-hatch synapses, rise times increased by a much smaller amount (Fig. $5 B$ ). At ages P2-3, increase in rise time during 20 stimulus trains was $28 \%$, and at ages P6-11 a 24\% increase was measured (Fig. 5C). Notably, EPSC rise times in P6-11 hatchlings after 20 stimuli at $200 \mathrm{~Hz}$ in P6-11 synapses are as fast $(0.19 \pm 0.01 \mathrm{msec})$ as rise times of the first EPSCs of trains at age E18 $(0.20 \pm 0.01 \mathrm{msec})$.

Progressive broadening of EPSCs during trains also declined with age (Fig. 5D). A large decrease in EPSC half-width was always seen between the first two EPSCs of a train associated with amplitude depression, so comparisons were made between the second and last EPSCs. The broader first EPSC is a result of its larger quantal content and consequent delayed clearance of transmitter from the synaptic cleft (Otis and Trussell, 1996). In E18 synapses, half-widths increased $33 \%$, from $0.59 \pm 0.02$ to $0.79 \pm 0.05$ msec. In P2-3 hatchlings, half-widths increased from $0.40 \pm 0.01$ to $0.49 \pm 0.02 \mathrm{msec}$, an increase of $22 \%$. In P6-11 hatchlings, half-widths increased by only $8 \%$, from $0.42 \pm 0.02$ to
$0.45 \pm 0.02 \mathrm{msec}$. Thus, not only are EPSCs at older synapses larger, but the time course of signaling remains more stable during high-frequency activity.

\section{Changes in mEPSCs with age}

To account for developmental changes in EPSCs and synaptic depression, further experiments were performed to measure quantal size $(q)$, vesicle pool size $(N)$, transmitter release probability $\left(P_{\mathrm{R}}\right)$, and the time course of recovery from synaptic depression $\left(\tau_{\text {REC }}\right)$. First, we recorded spontaneous mEPSCs in embryos and hatchlings to determine the contribution of changes in quantal size and kinetics to the changes we observed in evoked EPSCs. Average mEPSCs from an E18 neuron (average of 277 events) and a P3 neuron (average of 421 events) are illustrated in Figure $6 A$. Double-exponential functions were fit to the decay phase of the mEPSC and are superimposed on the averaged events in Figure $6 A$. Data from eight embryos (E18) and 11 hatchlings (P2-3) were analyzed (Fig. 6B). Amplitudes were significantly larger, and rise times and $\tau_{\text {FAST }}$ were significantly faster at P2-3 compared with E18 ( $p<0.01$; Student's $t$ test). The increase in mEPSC amplitude between E18 and P2-3 was 34\%, sufficient to account for part, but not all, of the developmental increase in EPSC amplitudes (Fig. 4). mEPSCs in P2-3 hatchlings were strikingly rapid, with a major exponential decay time constant of $0.120 \mathrm{msec}$. No significant differences in any parameters were seen in a comparison between mEPSCs obtained at P2-3 $(n=11)$ and P6-11 $(n=6)$. Thus, developmental changes in 
A

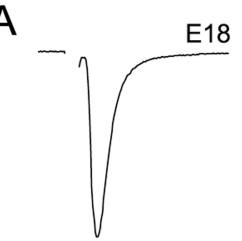

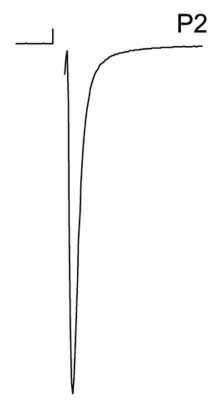

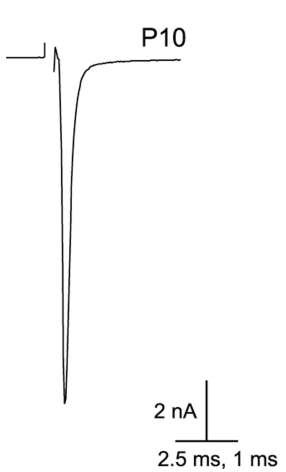

B

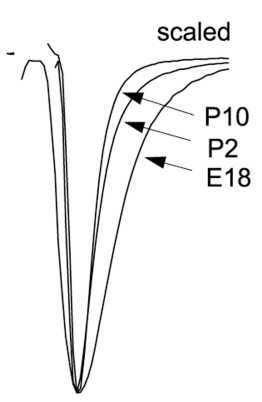

C

$$
\text { peak }(n A)
$$$$
\text { rise time }(\mathrm{ms})
$$

\begin{abstract}
half-width (ms)
\end{abstract}

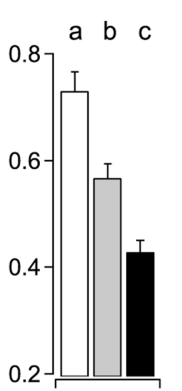

0.2
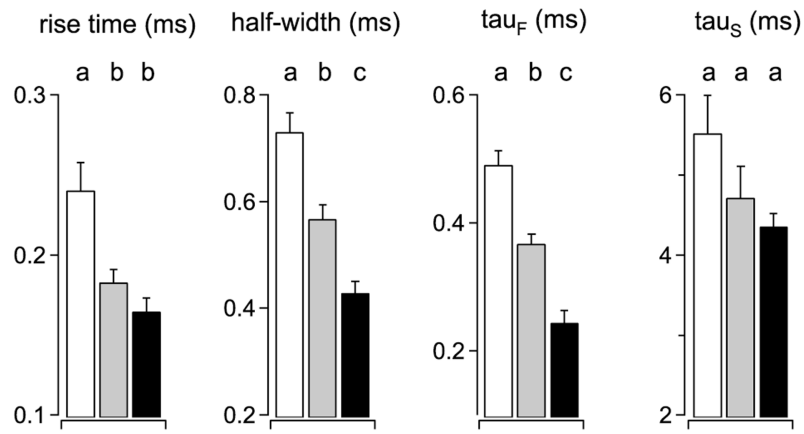

a $\quad b \quad b$

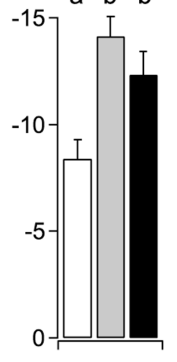

0.1

quanta are responsible in part for developmental changes in evoked EPSCs.

We next compared in hatchlings and embryos the effects on mEPSCs of aniracetam, a modulator of AMPA receptors that reduces desensitization (Vyklicky et al., 1991; Raman and Trussell, 1995; Partin et al., 1996). In addition to providing information about quantal size in the presence of aniracetam for vesicle pool measurements (see below), assaying sensitivity of mEPSCs to aniracetam could provide evidence for changes in AMPA receptor subunit composition during development (Partin

A

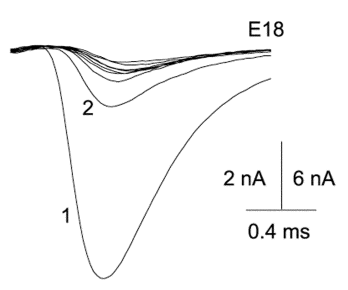

C

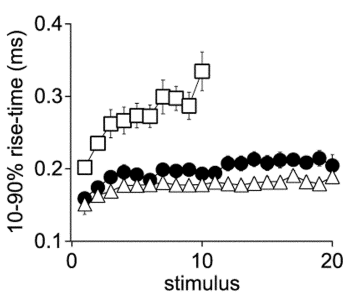

B
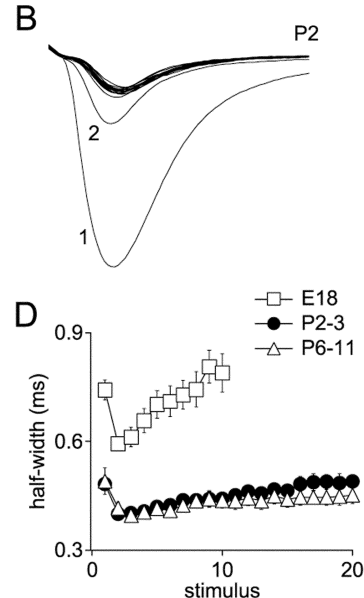

Figure 5. EPSC kinetics during trains stabilize with age. $A$, EPSCs from an E18 synapse during $200 \mathrm{~Hz}$ stimulation were superimposed to illustrate changes in rise times and half-widths. $B$, Superimposed EPSCs from a P2 synapse during $200 \mathrm{~Hz}$ stimulation. $C$, Progressive increase in $10-90 \%$ rise times of EPSCs during trains is reduced with age. $D$, Half-widths of EPSCs increase during trains in embryos but remain stable in post-hatch synapses.

et al., 1996). However, no significant differences with respect to changes in amplitude or decay time course were seen in the effect of aniracetam on mEPSCs in E18 versus P2-3 synapses (data not shown).

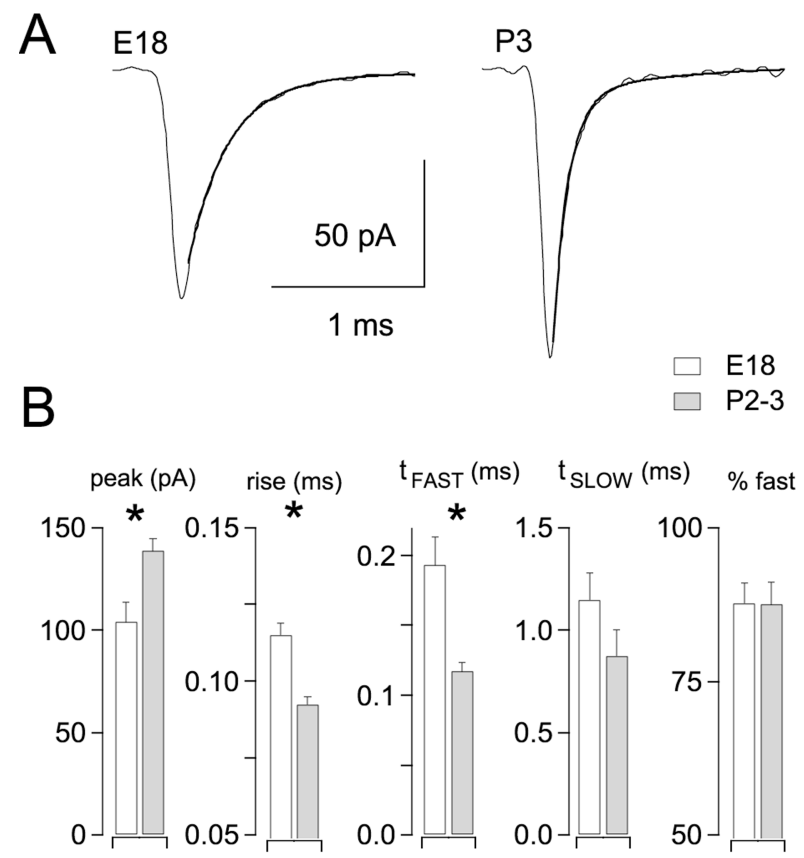

Figure 6. Increase in quantal size with development. $A$, Spontaneous mEPSCs were recorded in an E18 and a P3 neuron. Double exponential fits are superimposed on the decay of each averaged trace (gray lines). $B$, Averaged results from E18 $(n=8)$ and P2-3 $(n=12)$ neurons. Between 75 and 2148 events were averaged from each cell. Asterisks indicate statistically significant differences ( $p<0.01$; Student's $t$ test). 
A

Figure 7. Effects of aniracetam on synaptic depression. $A$, Stimulus train delivered at 333 $\mathrm{Hz}$ in control conditions and with $5 \mathrm{~mm}$ aniracetam. Traces were normalized to the amplitudes of the first peak in each train. Averages of three to five traces are shown. Inset shows EPSCs 14-17 of the stimulus train. $B$, Normalized peak amplitudes during stimulus trains delivered at $100 \mathrm{~Hz}(n=9$ neurons), $200 \mathrm{~Hz}(n=8)$, and $333 \mathrm{~Hz}(n=4)$ Circles, Control (con); triangles, aniracetam (ani). Depression was significantly reduced by aniracetam for stimulus 2 through 20 of trains. $C$, Relative enhancement of EPSC amplitudes by aniracetam throughout stimulus trains at $100 \mathrm{~Hz}$ (triangles), $200 \mathrm{~Hz}$ (circles), and $333 \mathrm{~Hz}$ (squares), calculated as $100 \%$. $\left(\mathrm{EPSC}_{\mathrm{ANI}}-\mathrm{EPSC}_{\mathrm{CON}}\right) / \mathrm{EPSC}_{\mathrm{CON}}$.
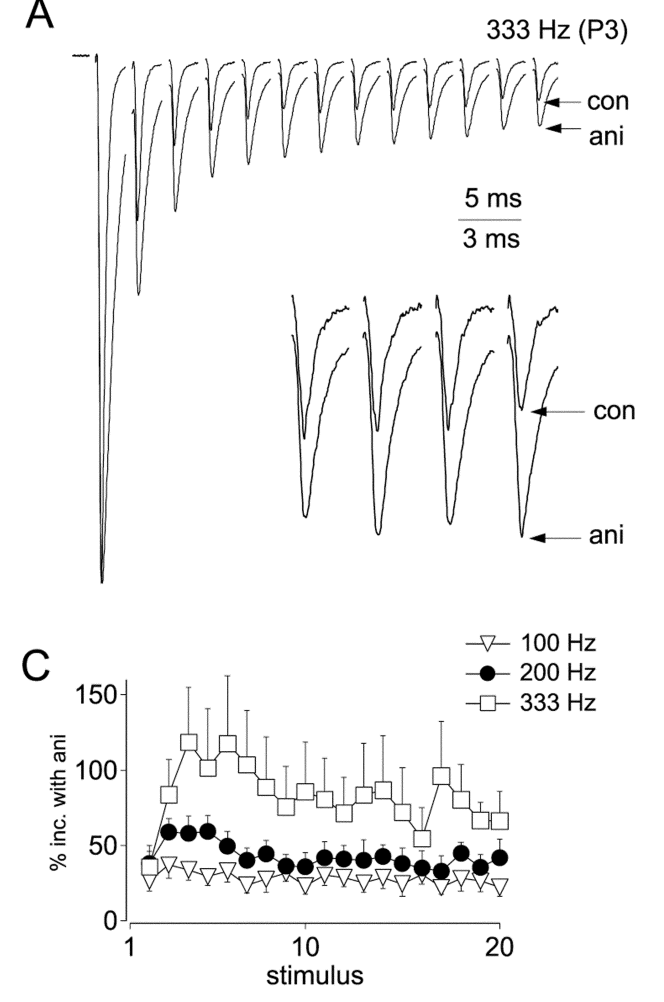
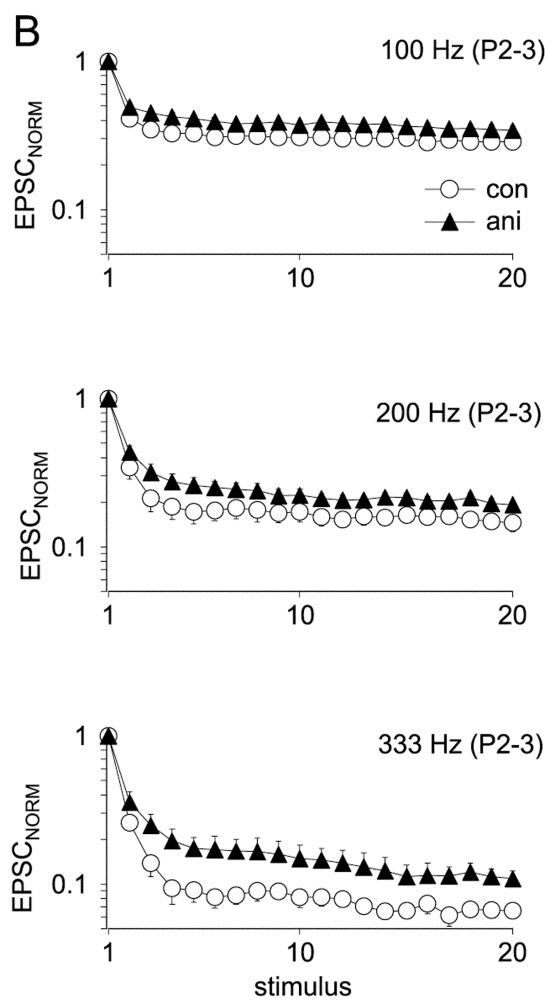

\section{Reduction of AMPA receptor desensitization in hatchlings during trains}

To determine the contribution of desensitization to synaptic depression in hatchlings, trains of EPSCs were recorded in control conditions and in the presence of aniracetam. Individual EPSCs were increased by aniracetam $(5 \mathrm{mM})$ from $12.4 \pm 1.1$ to $14.9 \pm 0.6 \mathrm{nA}(n=9)$, an increase of $25 \pm 8 \%$ (data not shown). This effect of aniracetam on EPSC amplitudes at age P2-3 was not significantly different from the effect seen at age E18 (35 \pm $5 \% ; n=18)$.

To determine the effect of aniracetam on synaptic depression, trains of EPSCs were normalized to the amplitude of the first peak (Fig. 7A). After normalization, depression was reduced in the presence of aniracetam compared with controls, an effect attributable to relief of desensitization. Normalized EPSC $_{\mathrm{SS}}$ (average of the last five EPSCs of trains) were larger in aniracetam at 100, 200, and $333 \mathrm{~Hz}$ (Fig. 7B) $(p<0.0001$; Mann-Whitney $U$ test). At 100, 200, and $333 \mathrm{~Hz}$, respectively, aniracetam enhanced EPSC $_{\text {Ss }}$ by $26 \pm 3,38 \pm 4$, and $73 \pm 10 \%$, respectively [calculated as $\left.100 \times\left(\mathrm{EPSC}_{\mathrm{ANI}}-\mathrm{EPSC}_{\mathrm{CON}}\right) / \mathrm{EPSC}_{\mathrm{CON}}\right]$. Thus, the amount of desensitization is dependent on stimulus frequency (Fig. $7 C$ ). Enhancement of $\mathrm{EPSC}_{\mathrm{SS}}$ by $38 \%$ indicates that $28 \%$ of synaptic AMPA receptors are desensitized during $200 \mathrm{~Hz}$ trains. By contrast, aniracetam enhancement of EPSCs in E18 synapses was $104 \pm 1 \%$ at $200 \mathrm{~Hz}$ (Brenowitz and Trussell, 2001), indicating that $51 \%$ of AMPA receptors are desensitized. Thus, the contribution of desensitization to synaptic depression during trains declines with age. Aniracetam does not completely block desensitization to a long pulse of a high concentration of glutamate (Raman and Trussell, 1995). However, it was most likely effective here, because the estimate of maximal desensitization in E18 synapses $(51 \%)$ made using aniracetam was similar to that provided through direct measurement of depression of quantal size (Brenowitz and Trussell, 2001).
Measurements of vesicle pools and release probability

To investigate presynaptic mechanisms that may contribute to the observed developmental changes in synaptic depression during stimulus trains, estimates of vesicle pool size and $P_{\mathrm{R}}$ were made at ages E18 and P2-3. This approach relied on a plot of the cumulative EPSC as a function of stimulus number during highfrequency trains (Schneggenburger et al., 1999; Wu and Borst, 1999; Bollmann et al., 2000). Because desensitization contributes to depression of EPSCs during trains (Fig. 7), pool size measurements were made in the presence of aniracetam. In some experiments on P2-3 hatchlings, 15-20 $\mu \mathrm{M}$ GYKI-52466, a noncompetitive AMPA receptor antagonist, was added to improve voltage clamp by reduction of EPSCs (see Materials and Methods). No effects of GYKI were seen on pool size measurements or on estimates of release probability, so pool size data from 12 neurons in aniracetam and 12 neurons in aniracetam and GYKI were combined for analysis. Quantal content of EPSCs was determined by dividing the peak synaptic currents by the quantal size. Quantal size was measured in the presence of $5 \mathrm{~mm}$ aniracetam in E18 and P2-3 synapses at $-60 \mathrm{mV}$ and corrected for a holding potential of $-30 \mathrm{mV}$ at which EPSCs were recorded. At $-60 \mathrm{mV}$, mEPSC amplitudes in $5 \mathrm{~mm}$ aniracetam for E18 and P2-3 synapses, respectively, were $129 \pm 9 \mathrm{pA}(n=8)$ and $180 \pm$ $14 \mathrm{pA}(n=11)$. To determine quantal size in $20 \mu \mathrm{M} \mathrm{GYKI}$, these values were further scaled by $64 \%$, the effect of $20 \mu \mathrm{M}$ GYKI on EPSC amplitudes. Using the steady-state region of the cumulative EPSC plot to extrapolate back to time 0 (stimulus 1), the initial size of the vesicle pool can be determined, under the assumption that EPSC recovery rates are uniform during the train (see below). With this method we find that the size of vesicle pools increased 44\%, from $209 \pm 14$ to $291 \pm 19$ between ages E18 and P2-3 (data not shown). This change was highly significant ( $p<$ 0.001 ; Student's $t$ test). Release probability was determined by 


\begin{tabular}{lcc}
\hline \multicolumn{3}{l}{ Table 1. Developmental changes in EPSC parameters } \\
& E18 & P2-3 \\
\hline$q(-30 \mathrm{mV})$ & $57 \pm 5 \mathrm{pA}$ & $80 \pm 3 \mathrm{pA}$ \\
$N$ & $209 \pm 14$ & $291 \pm 19$ \\
$P_{\mathrm{R}}$ & $0.69 \pm 0.01$ & $0.53 \pm 0.03$ \\
Predicted EPSC $\left(N \cdot P_{\mathrm{R}} \cdot q\right)$ & $8.2 \mathrm{nA}$ & $12.3 \mathrm{nA}$ \\
Measured EPSC & $8.4 \pm 0.9 \mathrm{nA}$ & $12.5 \pm 0.9 \mathrm{nA}$ \\
Steady-state desensitiza- & & \\
$\quad$ tion at $200 \mathrm{~Hz}$ & $51 \%$ & $28 \%$ \\
EPSC $_{\mathrm{SS}}$ at $200 \mathrm{~Hz}$ & $0.52 \pm 0.02 \mathrm{nA}$ & $2.53 \pm 0.02 \mathrm{nA}$ \\
\hline
\end{tabular}

calculating the ratio between the quantal content of the first EPSC of the train and the total pool size. $P_{\mathrm{R}}$ declined $17 \%$, from $0.69 \pm 0.01$ to $0.53 \pm 0.03$ during this developmental period $(p<$ 0.001; Mann-Whitney $U$ test).

Using a related method based on a plot of the relationship between quantal content of the EPSC and cumulative quantal content of the train (Elmqvist and Quastel, 1965; Christensen and Martin, 1970; Lu and Trussell, 2000), similar results were obtained (data not shown). Although both methods use similar approaches, relying on extrapolation of plots based on EPSC trains, the regions of the trains used for extrapolation differ between the two methods. Unlike the cumulative EPSC plot used above, the method of Christensen and Martin (1970) relies on data points during the initial (pre-steady-state) portion of the stimulus trains and is insensitive to effects of a slow phase of depression (Fig. 3C, asterisk). Using this approach, the estimated increase in the vesicle pool size was $69 \%$, and release probability declined by $26 \%$. These changes were highly significant $(p<$ 0.001 ; Mann-Whitney $U$ test for $P_{\mathrm{R}}$, Student's $t$ test for pool size). Increased vesicle pool size and reduced $P_{\mathrm{R}}$ are expected to reduce synaptic depression and thereby improve sustained highfrequency transmission at the nMag end-bulb synapse.

The developmental decline in $P_{\mathrm{R}}$ suggests that transmitter release should become more sensitive to decreases in extracellular calcium (i.e., a rightward shift in the dose-response relationship between calcium and release). Therefore we predicted that lowering extracellular calcium should cause a larger reduction of EPSC amplitudes in hatchlings compared with embryos. Consistent with this hypothesis, we found that lowering bath calcium from 3 to $1.5 \mathrm{~mm}$ had a greater effect in hatchlings, reducing EPSCs by $26 \pm 4 \%$ in E18 synapses $(n=3)$ and by $37 \pm 2 \%$ in hatchlings $(n=11 ; p<0.05$; Student's $t$ test).

Developmental changes in quantal parameters are summarized in Table 1. Quantal sizes were scaled for a holding potential of $-30 \mathrm{mV}$. Values of $N$ and $P_{\mathrm{R}}$ were obtained from the cumulative EPSC plots (Fig. $7 A-C$ ). EPSC amplitudes were determined in a population of 8 embryos (E18) and 11 hatchlings (P2-3) from which mEPSCs were also recorded.

Close agreement was observed between EPSC amplitudes predicted by the product $N \cdot P_{\mathrm{R}} \cdot q$ and experimentally measured values.

\section{Recovery from synaptic depression}

An additional factor that determines the amplitudes of synaptic responses during repetitive stimulation is the rate of recovery from synaptic depression (O’Donovan and Rinzel, 1997; Dittman and Regehr, 1998). Therefore we performed a series of experiments to monitor recovery rates (determined by recovery of
EPSC amplitudes), under different conditions. These experiments were designed to investigate developmental changes, as well as effects of conditioning stimuli and calcium on rates of recovery from synaptic depression.

Recovery from single conditioning stimuli was compared in E18 and P2-3 synapses (Fig. 8). To determine the amount and time course of desensitization after a single conditioning stimulus, these experiments were conducted in the absence and presence of aniracetam. In the continuous presence of GYKI-52466 (see Materials and Methods), recovery was monitored between 5 msec and $5 \mathrm{sec}$. Recovery from 5 to $50 \mathrm{msec}$ is shown for E18 and P2 synapses in Figure 8, $A$ and $B$, respectively. EPSCs recorded in control conditions and in aniracetam were normalized and superimposed. Average recovery data for E18 and P2-3 synapses is shown in Figure 8, $C$ and $D$, respectively. Recovery for E18 and P2-3 synapses is superimposed for comparison in Figure $8 E, F$. The $\mathrm{EPSC}_{2} / \mathrm{EPSC}_{1}$ ratio in GYKI-52466 at a $5 \mathrm{msec}$ stimulus interval was $0.12 \pm 0.02$ at E18 and $0.37 \pm 0.04$ at P2-3. Thus, paired-pulse depression with a $5 \mathrm{msec}$ stimulus interval was reduced by a factor of 3 in P2-3 versus E18 synapses.

When recovery was monitored in the presence of aniracetam, a large difference in the amount of desensitization between embryos and hatchlings became apparent (Fig. 8C,D, insets), in agreement with previous results using train stimulation (Fig. 7). In E18 synapses (Fig. 8C) aniracetam significantly reduced depression at intervals of 5-30 msec $(p<0.006$; Wilcoxon signed rank test), but with stimulus intervals $>30 \mathrm{msec}$, depression in control and aniracetam were not significantly different. In P2-3 synapses, significant effects of aniracetam on depression persisted through the 5 and $10 \mathrm{msec}$ recovery intervals, but with a $20 \mathrm{msec}$ interval, PPD was not affected by aniracetam (Fig. 8D). Thus desensitization is greater and more persistent in embryos than in hatchlings. At both ages, recovery from desensitization contributed to the fast component of EPSC recovery but did not affect the slow component. However, the effect of aniracetam on the fast component was greatest in embryos (Fig. $8 C, D$ ). Reduced desensitization after hatching is consistent with our earlier measurement of lower $P_{\mathrm{R}}$ because we have shown previously that desensitization is minimal when release probability is lowered (Brenowitz and Trussell, 2001). Recovery from desensitization, measured as decay in the enhancement of $\mathrm{EPSC}_{2} / \mathrm{EPSC}_{1}$ by aniracetam, is shown in Figure $8 G$. At near-physiological recording temperatures $\left(34-36^{\circ} \mathrm{C}\right)$, recovery from effects of aniracetam proceeded with a time course of $<10 \mathrm{msec}$ in E18 and P2-3 synapses, suggesting rapid unbinding and clearance of glutamate.

Figure $8 E$ illustrates recovery from synaptic depression that consists of both presynaptic and postsynaptic components. By blocking desensitization with aniracetam, presynaptic components of recovery could be observed in isolation (Fig. 8F). A fast component of presynaptic recovery persisted in hatchlings and embryos. The rate and amplitude of slow recovery components and the rate of the fast component did not change appreciably with age (Fig. 8, see legend). The main developmental change in recovery after a single stimulus was the magnitude of the fast recovery component, which decreased from 59 to $36 \%$ between E18 and P2-3 (Fig. 8E,F). The remaining fast component of recovery in the presence of $5 \mathrm{~mm}$ aniracetam is unlikely to result from residual desensitization that is resistant to aniracetam, because in a group of four hatchling neurons that did not show any effects of aniracetam on depression ("nondesensitizing"), a fast component of recovery was still present (data not shown). Moreover, the rate of this component $(\sim 35 \mathrm{msec})$ is more than three- 
A

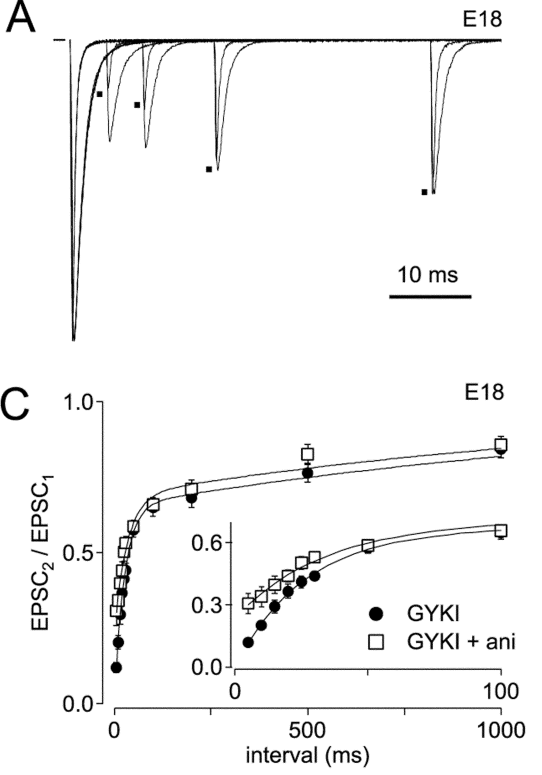

B

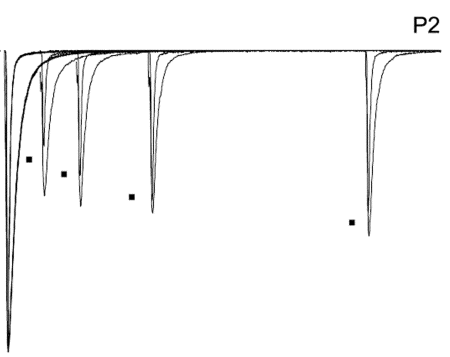

$\mathrm{D}$

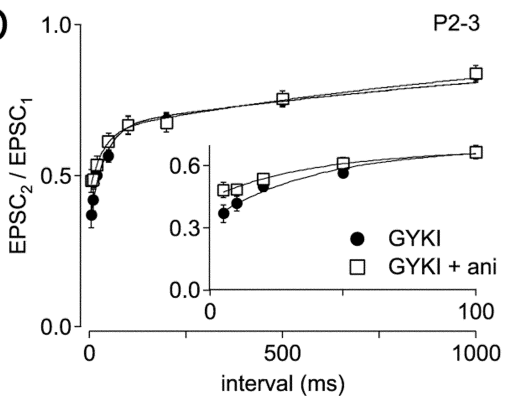

E

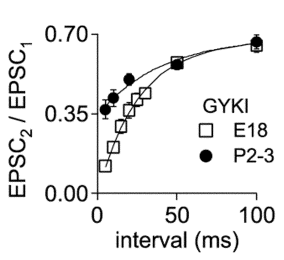

$\mathrm{F}$

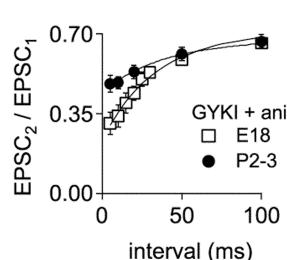

G

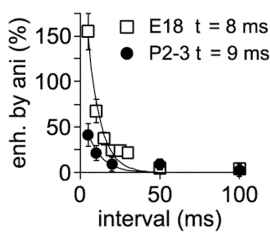

Figure 8. Time course of recovery from synaptic depression after a single stimulus. $A$, Recovery was monitored by test pulses at intervals of 5 msec to $5 \mathrm{sec}$ after one conditioning stimulus in an E18 synapse. Traces showing recovery in the presence GYKI (peaks indicated by dots) and in GYKI + aniracetam were normalized and superimposed. For these experiments, $20 \mu \mathrm{M}$ GYKI was used to improve voltage clamp. B, Recovery in GYKI (indicated by dots) and GYKI + aniracetam is shown for a P2 synapse. C, Summary of recovery data for E18 synapses $(n=10)$, in GYKI (squares) and GYKI + aniracetam (circles). Data points were fit with double-exponential functions. Inset shows recovery from 5 to $100 \mathrm{msec}$ on an expanded time scale. For recovery of E18 synapses in GYKI, $\tau_{\text {fast }}=26 \mathrm{msec}, \tau_{\text {slow }}=1.5 \mathrm{sec}$, and \%fast $=65 \%$. For recovery of E18 synapses in GYKI + aniracetam, $\tau_{\text {fast }}=$ $33 \mathrm{msec}, \tau_{\text {slow }}=1.4 \mathrm{sec}$, and \%fast $=59 \%$. D, Recovery in P2-3 synapses $(n=11)$ in GYKI (squares) and GYKI + aniracetam (circles). Inset shows recovery from 5 to $100 \mathrm{msec}$ on an expanded time scale. For recovery of P2-3 synapses in GYKI, $\tau_{\text {fast }}=35 \mathrm{msec}, \tau_{\text {slow }}=1.8 \mathrm{sec}$, and $\%$ fast $=47 \%$. For recovery of P2-3 synapses in GYKI + aniracetam, $\tau_{\text {fast }}=35 \mathrm{msec}, \tau_{\text {slow }}=1.5 \mathrm{sec}$, and $\%$ fast $=36 \%$. E, Comparison of depression and recovery in E18 and P2-3 synapses in GYKI. With a 5 msec recovery interval, EPSC $2 / \mathrm{EPSC}_{1}$ ratio was $0.12 \pm 0.02$ and $0.37 \pm 0.04$ at ages E18 and P2-3, respectively. $F$, Comparison of recovery in E18 and P2-3 synapses in GYKI + aniracetam. With a $5 \mathrm{msec}$ recovery interval, EPSC $2 / \mathrm{EPSC}_{1}$ ratio was $0.31 \pm 0.05$ and $0.48 \pm 0.04$ at ages E18 and P2-3, respectively. $G$, Relative enhancement of EPSCs by aniracetam is plotted versus recovery interval. Enhancement is calculated as $\left(\mathrm{EPSC}_{\mathrm{GYKI} I-\mathrm{ANI}} / \mathrm{EPSC}_{\mathrm{GYKI}}\right) / \mathrm{EPSC}_{\mathrm{GYKI}}$.

fold slower than recovery of aniracetam-sensitive depression (Fig. $8 G)$. The multiple components of recovery may indicate the presence of multiple vesicle pools or multiple kinetic steps involved in replenishment of a releasable pool. Mechanisms of depression other than depletion, such as refractoriness of release, may also contribute to recovery rates.

\section{Recovery of EPSCs after multiple conditioning stimuli}

Because the auditory nerve exhibits both spontaneous and acoustically driven activity, we examined recovery from multiple conditioning stimuli to determine how ongoing activity may affect recovery rates. After 10 stimuli at $200 \mathrm{~Hz}$, test EPSCs were evoked at recovery intervals ranging from $5 \mathrm{msec}$ to $5 \mathrm{sec}$. Data from a $\mathrm{P} 3$ neuron are shown in Figure $9 A$. In P2-3 synapses, although the total amount of depression was increased threefold by the conditioning train, the time course of recovery was not affected, as indicated by superposition of scaled recovery curves (Fig. 9E). However, in E18 synapses the conditioning train caused a twofold slowing of the fast component of recovery, from 26 to $53 \mathrm{msec}$ (Fig. 9D). A small increase in the contribution of the fast component to recovery was also seen (Fig. $9 F$ ).

To summarize, EPSC recovery after trains was bi-exponential and exhibited a fast $(<100 \mathrm{msec})$ component at both ages. This fast recovery component resulted from both presynaptic recovery and recovery from AMPA receptor desensitization. Improved high-frequency transmission in hatchlings is thus achieved in part by acquisition of "stable" recovery rates that do not exhibit activity-dependent slowing during repetitive stimulation. In em- bryonic synapses, a slowing of $\tau_{\text {FAST }}$ caused by activity is predicted to underlie the slow phase of depression (Fig. 3C, asterisk). In addition, the contribution of desensitization to the fast component of depression and recovery declines with age.

\section{Recovery in reduced extracellular calcium}

Calcium entry into the presynaptic terminal has been shown to affect rates of vesicle cycling in other synapses (Dittman and Regehr, 1998; Wang and Kaczmarek, 1998; Wang and Zucker, 1998), suggesting that the fast phase of recovery seen at the nMag synapse may be induced by elevated presynaptic calcium. If so, we predicted that recovery would be slowed if extracellular calcium were reduced. However, when we measured recovery from depression in low extracellular $(1.5 \mathrm{~mm})$ calcium after conditioning trains of 1, 5, and 16 stimuli delivered at $333 \mathrm{~Hz}$ (data not shown), a fast component of recovery remained. The time constant of recovery after conditioning trains of 1, 5 and 16 stimuli was 22, 24, and $27 \mathrm{msec}$, respectively. The contribution of the fast component to recovery (percentage fast) after 1,5 , and 16 conditioning stimuli was 39,58 , and $59 \%$. Thus, fast recovery persisted under the lowest levels of presynaptic calcium influx that were tested.

\section{Membrane properties of post-hatch neurons}

Current-clamp experiments were conducted to examine responses of post-hatch nMag neurons to current steps. The membrane response in hatchlings is very similar to that in embryos, being characterized by generation of a single spike and strong outward rectification (Reyes et al., 1994; Zhang and Trussell, 


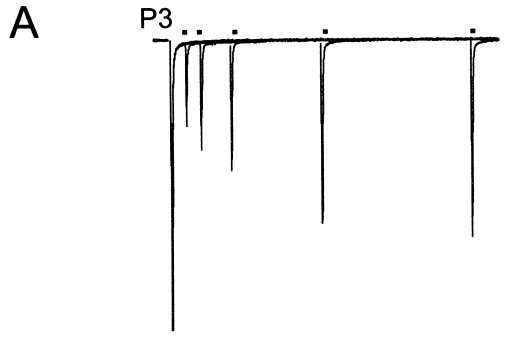

B

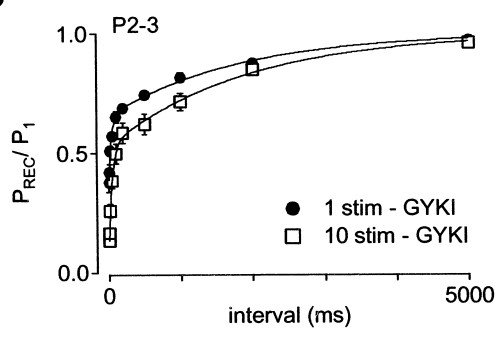

P3

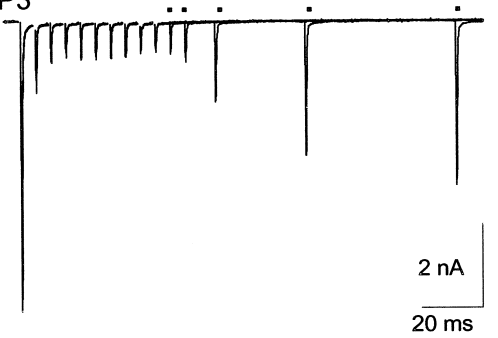

C

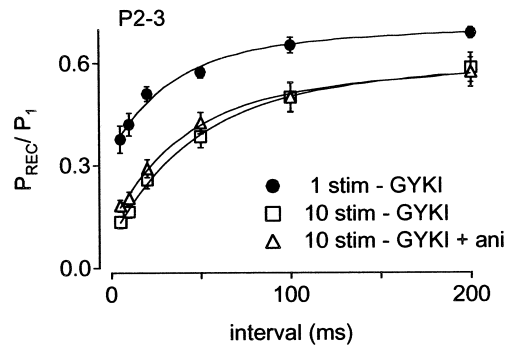

D

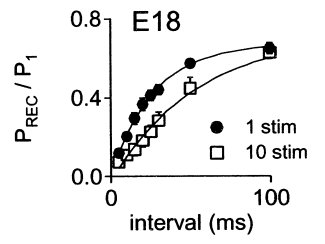

E

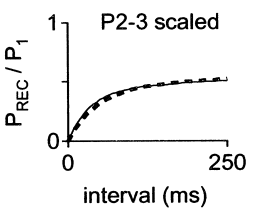

$\mathrm{F}$

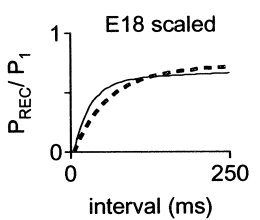

Figure 9. Recovery from synaptic depression after trains of stimuli. $A$, Recovery was monitored after conditioning by 1 (left) or 10 (right) stimuli delivered at $200 \mathrm{~Hz}$. Stimuli delivered to monitor recovery are indicated by dots above traces. $B$, Summary of recovery from 1 stimulus $($ circles; $n=16$ neurons) and 10 stimuli (squares; $n=15$ neurons) in GYKI, from $5 \mathrm{msec}$ to $5 \mathrm{sec}$ in P2-3 hatchlings. For recovery after 10 stimuli in GYKI, parameters of a double-exponential fit to the data points were $\tau_{\text {fast }}=46 \mathrm{msec}, \tau_{\text {slow }}=1.9$, and $\%$ fast $=48 \%$. For recovery after 10 stimuli in GYKI + aniracetam, parameters were $\tau_{\text {fast }}=39 \mathrm{msec}, \tau_{\text {slow }}=1.5$, and $\%$ fast $=43 \%$. C, Data from $B$ on an expanded time scale. Also shown is recovery from 10 stimuli in GYKI + aniracetam (triangles; $n=5$ neurons). $D$, Recovery from depression in E18 synapses after 1 (squares; $n=10)$ and 10 stimuli $($ circles; $n=7$ ) at $200 \mathrm{~Hz}$. For recovery of E18 synapses after 10 stimuli in GYKI, double-exponential fit parameters were $\tau_{\text {fast }}=53$ msec, $\tau_{\text {slow }}=2.1$, and $\%$ fast $=71 \%$. $E$, Double-exponential fits of hatchling recovery data from $B$ were normalized and superimposed to illustrate that relative time course of recovery did not change. $F$, Double-exponential fits of embryo recovery data from $D$ were scaled and superimposed to illustrate that trains increased and slowed the fast component of depression. Dashed line in $E$ and $F$ indicates recovery after trains. Solid line in $E$ and $F$ indicates recovery after single stimulus.

1994b). The current-voltage relationship was measured for a group of eight neurons of ages $\mathrm{P} 2-3$ (data not shown). Our results indicate that input resistance of nMag neurons in P2-6 neurons declined threefold compared with E18 neurons (Zhang and Trussell, 1994b). Membrane capacitance also increased with development. $C_{\mathrm{M}}$ increased from $11.9 \pm 0.5 \mathrm{pF}$ at E18 $(n=31)$ to $14.8 \pm 0.7 \mathrm{pF}$ in $\mathrm{P} 2-11$ hatchlings $(n=31)$, a change of $24 \%(p<$ 0.001 ; Student's $t$ test).

Action potential generation required larger current injections in post-hatch nMag neurons. Threshold was reached with current injections of $1.05 \pm 0.06 \mathrm{nA}(n=20$; data not shown), compared with $0.43 \pm 0.12 \mathrm{nA}$ in embryos (Zhang and Trussell, 1994b). This suggests that larger synaptic conductances would be required for action potential generation in older animals. Thus, despite the increase in spike threshold and shorter duration of synaptic currents (Fig. 4), developmental increases in $\mathrm{EPSC}_{\mathrm{SS}}$ during trains enable sustained high-frequency transmission.

\section{Effects of $\mathrm{GABA}_{\mathrm{B}}$ receptors on synaptic transmission in hatchlings}

Previously we demonstrated in embryonic nMag that $\mathrm{GABA}_{\mathrm{B}}$ receptors enhance EPSC amplitudes during high-frequency trains (Brenowitz et al., 1998), attributable to relief of AMPA receptor desensitization (Brenowitz and Trussell, 2001). Because desensitization was reduced in hatchlings compared with embryos, we performed experiments to examine effects of $\mathrm{GABA}_{\mathrm{B}}$ receptor activation on synaptic depression in hatchlings during trains (Fig. 10). EPSCs were recorded under control conditions and in the presence of a saturating concentration of baclofen $(100 \mu \mathrm{M})$, a $\mathrm{GABA}_{\mathrm{B}}$ receptor agonist. Single EPSCs were reduced by $84 \pm$ $3 \%$ in E18 synapses $(n=6)$ (Brenowitz and Trussell, 2001) and by $76 \pm 6 \%$ in P3-6 synapses $(n=6)$. These effects of baclofen on embryos versus hatchlings were not significantly different $(p>$ 0.05; Mann-Whitney $U$ test).

Next, we delivered trains of stimuli at $200 \mathrm{~Hz}$ to P3-6 synapses in control conditions and in baclofen (Fig. 10A). Amplitudes of EPSCs recorded in both conditions converged on the same steady-state value after two to three stimuli (Fig. 10A,C), and amplitudes maintained the same values for the remainder of the 20-stimulus trains, suggesting equivalent levels of AMPA receptor desensitization in baclofen and control conditions. When stimulus rates were increased to $333 \mathrm{~Hz}$, however, EPSCs in baclofen became larger than control EPSCs after two to three stimuli and remained larger for the duration of the train (Fig. $10 B, C)$. By contrast, baclofen enhanced by more than twofold EPSCs evoked at $200 \mathrm{~Hz}$ in E18 synapses (Fig. 10D).

Because enhancement of synaptic strength by $\mathrm{GABA}_{\mathrm{B}}$ receptor activation was observed in post-hatch synapses only at high frequencies that are in the upper range of chick auditory nerve firing rates, we investigated alternative roles of $\mathrm{GABA}_{\mathrm{B}}$ receptors in auditory signal processing. Because deterioration of rapid EPSC kinetics during trains will limit temporal accuracy and maximum rates of postsynaptic action potential firing, we examined effects of baclofen on EPSC rise times and half-widths during $200 \mathrm{~Hz}$ trains (Fig. 10E,F). Rise times were significantly faster in baclofen compared with control for stimuli 2-20 of trains $(p<0.05$; paired $t$ tests). Half-widths of EPSCs were also significantly reduced by baclofen ( $p<0.01$; paired $t$ tests). Thus, $\mathrm{GABA}_{\mathrm{B}}$ receptors at the nMag end-bulb synapse in hatchlings may accelerate the time course of the EPSC during high-frequency repetitive firing. At frequencies approaching the maximum reported firing rates for avian auditory nerve fibers $(200-300 \mathrm{~Hz}$ ) (Manley et al., 1991; Salvi et al., 1992), GABA B $_{\text {receptor activation will }}$ 
Figure 10. Effects of $\mathrm{GABA}_{\mathrm{B}}$ receptor activation on synaptic depression in P3-6 neurons. A, Top traces, Stimulus trains were delivered to a $\mathrm{P} 6$ synapse at $200 \mathrm{~Hz}$ in the absence (con) or presence (bac) of $100 \mu \mathrm{M}$ baclofen. Bottom traces, EPSCs 11-20 were superimposed and displayed on an expanded time scale to illustrate convergence of steadystate EPSC amplitudes. B, Top traces, Trains at $333 \mathrm{~Hz}$ in control (con) and baclofen (bac). Bottom traces, EPSCs 11-20 are superimposed and displayed on an expanded time scale to illustrate enhancement of EPSC amplitudes by baclofen at $333 \mathrm{~Hz}$. C, Ratios of EPSCs in baclofen versus control $\left(b a c_{\mathrm{N}} /\right.$ $\operatorname{con}_{\mathrm{N}}$ ) for each stimulus of trains delivered at $100 \mathrm{~Hz}$ (triangles), $200 \mathrm{~Hz}$ (squares), and 333 $\mathrm{Hz}$ (circles) in P3-6 neurons $(n=6)$. At steady state, $b a c_{\mathrm{N}} / \mathrm{con}_{\mathrm{N}}$ was $0.66,1.0$, and 1.45 at 100,200 , and $333 \mathrm{~Hz}$, respectively. $D$, Comparison of $\left(\mathrm{bac}_{\mathrm{N}} / \mathrm{con}_{\mathrm{N}}\right)$ ratio at $200 \mathrm{~Hz}$ at P3-6 and E18. For E18 synapses, the steadystate value of $b a c_{\mathrm{N}} / \mathrm{con}_{\mathrm{N}}$ (average of last 3 stimuli) at $200 \mathrm{~Hz}$ was $2.0 \pm 0.2(n=8) . E$, Rise times (10-90\%) of EPSCs during 200 $\mathrm{Hz}$ stimulus trains in $\mathrm{P} 3-6$ neurons in control conditions (con, triangles) and in the presence of baclofen (bac, squares). Rise times remain faster during trains in the presence of baclofen. $F$, Half-widths of EPSCs during 200 $\mathrm{Hz}$ trains are narrower in baclofen (squares) compared with control (triangles).
A

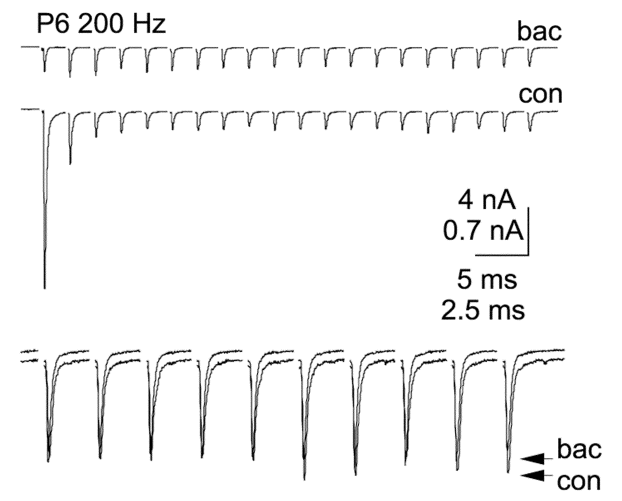

B

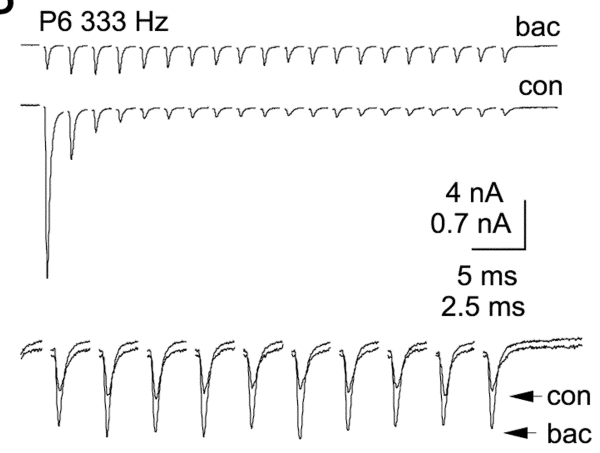

C

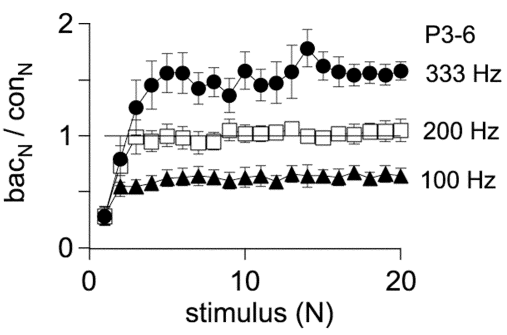

$\mathrm{D}$
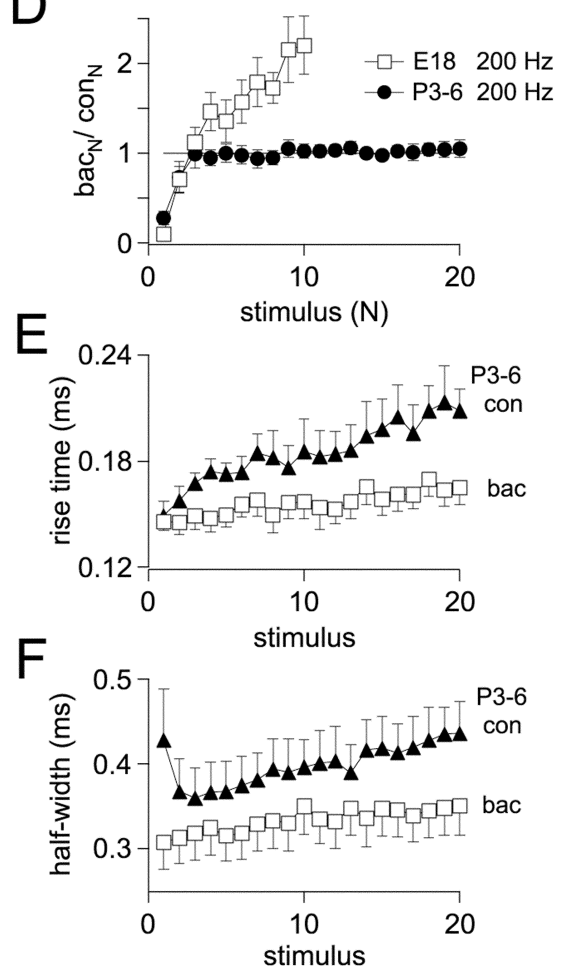

also serve to enhance synaptic strength and promote suprathreshold transmission.

\section{DISCUSSION}

In this work we have described physiological changes at the nMag end-bulb synapse that occur around the time of hatching and result in dramatic improvement in reliability and timing of highfrequency synaptic transmission. These changes include an increase in EPSC amplitude, faster rise and decay kinetics of EPSCs, reduced synaptic depression during stimulus trains, and lower input resistance. Contributing to these changes are larger and faster mEPSCs, a larger pool of transmitter vesicles, lowered probability of transmitter release, and reduced AMPA receptor desensitization during trains, as summarized in Table 1. Rates of recovery from synaptic depression during repetitive stimulation are also more stable in older synapses. The improved reliability and timing of postsynaptic action potentials during stimulus trains promote suprathreshold transmission at frequencies reaching the upper limit of auditory nerve activity.

Improvements in high-frequency transmission during development have been observed at other synapses of the auditory pathway. In rodents, the onset of hearing occurs between P10 and P14 (Mikaelian and Ruben, 1964), but auditory nerve responses do not appear adult-like until P18-36 (Sanes and ConstantinePaton, 1985; Blatchley et al., 1987).
Various changes at auditory synapses have been described that accompany the onset of neural activity in the auditory system. $\mathrm{Wu}$ and Oertel (1987) reported a developmental decrease in input resistance and improved responses to repetitive stimulation between P7 and P22 in the mouse cochlear nucleus, consistent with findings of this study. Bellingham and Walmsley (1997) report increased mEPSC and evoked EPSC amplitudes in the rat cochlear nucleus between $\mathrm{P} 4$ and P18, also consistent with our results. In contrast, no changes in mEPSC or evoked EPSC amplitudes were found in rat MNTB (Taschenberger and von Gersdorff, 2000; Iwasaki and Takahashi, 2001). However, at the mouse calyx of Held, Futai et al. (2001) report a severalfold increase in EPSC amplitudes between P5 and P27. Acceleration of EPSC kinetics at auditory synapses during development has also been reported by Taschenberger and von Gersdorff (2000), Futai et al. (2001), and Iwasaki and Takahashi (2001). Acquisition of rapid AMPA-mediated EPSC kinetics may result from postsynaptic alterations in receptor subunit composition (Lawrence and Trussell, 2000) and faster presynaptic action potential waveforms (Taschenberger and von Gersdorff, 2000). In the embryonic avian nMag, NMDA receptors do not contribute substantially to synaptic signaling (Zhang and Trussell, 1994b) and were not investigated in this study. Larger vesicle pools and reduced $P_{\mathrm{R}}$ also contribute to maturation of transmission at the calyx of Held 
(Taschenberger and von Gersdorff, 2000; Iwasaki and Takahashi, 2001). In hippocampus, reduced $P_{\mathrm{R}}$ also occurs during development (Chavis and Westbrook, 2001). Acquisition of rapid EPSC kinetics and stable high-frequency transmission as auditory activity increases during development appear to be common features of auditory synapses. Recent work (Lawrence and Trussell, 2000; Futai et al., 2001) provides evidence that these changes may result from intrinsic developmental processes as well as from increased synaptic activity.

Developmental changes in recovery from synaptic depression included a decline in the overall magnitude of depression and a decrease in the relative amount of the fast recovery component. Thus, changes in recovery time course were apparent only at intervals up to $50 \mathrm{msec}$. This suggests that a developmental decline in the amount of synaptic depression should be present with high stimulus rates but should not be apparent during lowfrequency stimulation (less than $\sim 20 \mathrm{~Hz}$ ). In fact, such an effect was apparent in our results (Fig. 3C), which indicate that the decline in synaptic depression between E18 and P6-11 was more pronounced at $333 \mathrm{~Hz}$ than at $100 \mathrm{~Hz}$. Because $P_{\mathrm{R}}$ is higher in embryos, such findings may indicate a population of vesicles that is more "releasable" and recovers more readily but declines in size with age. The dramatic reduction in synaptic depression (Fig. 3 ) and trend toward smaller EPSCs (Fig. 4) between P2-3 and P6-11 suggest that further changes in $P_{\mathrm{R}}$ and vesicle recovery rates may occur between these ages. In this study recovery was not examined in older (P6-11) hatchlings.

Although a fast component of recovery from depression $(<100$ msec) was present in nMag, at the rat calyx of Held in the MNTB (P8-10) only a slow phase of recovery was apparent (Schneggenburger et al., 1999; Wu and Borst, 1999). In mouse (P12-15), Wang and Kaczmarek (1998) also report a single, slow recovery time constant (5.0 sec at room temperature) after $100 \mathrm{~Hz}$ stimulation. However, when stimulus rates were increased to $300 \mathrm{~Hz}$, elevated calcium levels in the presynaptic terminal induced a fast (84 msec at room temperature, $43 \%$ fast) phase of recovery. A calcium-dependent fast component of recovery (100 msec at room temperature, $44 \mathrm{msec}$ at $34^{\circ} \mathrm{C}$ ) after a single stimulus was also present at the climbing fiber-Purkinje cell synapse, but in low (1 $\mathrm{mm}$ ) calcium, recovery was monoexponential with a time course of $3.6 \mathrm{sec}$ at room temperature (Dittman and Regehr, 1998). Recently, Iwasaki and Takahashi (2001) reported in rat MNTB that no developmental change occurs in the time course of recovery from depression after $10 \mathrm{~Hz}$ stimulation. However, with low-frequency stimulation, fast components of recovery are not apparent at the calyx of Held (Wang and Kaczmarek, 1998). Our findings indicate a developmental decrease in the fast component of recovery after both single stimuli and trains.

Recovery in nMag differs from these examples in that a fast component of recovery was present after single or multiple conditioning stimuli in standard $(3 \mathrm{~mm})$ or reduced $(1.5 \mathrm{~mm})$ calcium. The persistence of a fast recovery component in $1.5 \mathrm{~mm}$ calcium suggests that a calcium-dependent recovery mechanism may be saturated by low levels of presynaptic calcium and therefore may not influence recovery with realistic activity rates. Mechanisms for fast recovery, whether constitutively active or calcium dependent, may be a common feature of auditory synapses, enabling sustained and rapid signaling.

The values obtained in this study for quantal parameters $N, P_{\mathrm{R}}$, and $q$, as well as the rate of recovery from synaptic depression, allow comparison between experimentally measured EPSCs and predictions of a depletion model of synaptic depression (Dittman and Regehr, 1998; Weis et al., 1999; Brenowitz and Trussell, 2001). As shown in Table 1, both E18 and P2-3 synapses show agreement between measured EPSCs and predicted amplitudes on the basis of parameters obtained in this study. Moreover, experimentally measured PPD agrees closely with predictions based on a depletion model, as described in Brenowitz et al. (2001). For P2-3 synapses, PPD in aniracetam with a $5 \mathrm{msec}$ stimulus interval was $0.44 \pm 0.05$ (Fig. 7) compared with a prediction of 0.46 when parameters from this study were used. Close agreement between observed and predicted EPSCs and PPD was also seen with embryonic synapses. However, experimentally measured steady-state EPSCs during trains were consistently larger than predictions of a depletion model (Brenowitz and Trussell, 2001), using recovery rates measured in this study, by a factor of 2 . The developmental increase in observed steadystate EPSC amplitudes can be attributed to lower $P_{\mathrm{R}}$, less desensitization, and disappearance of a persistent slow component of depression seen in embryos (Fig. 3B,C) (Brenowitz and Trussell, 2001, their Fig. 4). Discrepancies between the predicted and observed amplitudes may indicate that activity-dependent recovery mechanisms are present but were not revealed when recovery was monitored with single test pulses (Fig. 9). Previous studies at the calyx of Held (Weis et al., 1999) also indicated that measured recovery rates predict smaller EPSCs than observed experimentally, and these authors also failed to observe evidence for calcium-dependence of recovery. Such findings may demonstrate shortcomings of using depletion models to describe synaptic transmission (Kraushaar and Jonas, 2000; Matveev and Wang, 2000). Alternatively, these observations may provide evidence for activity-dependent enhancement of recovery from synaptic depression that operates by a calcium-independent mechanism.

\section{REFERENCES}

Bellingham MC, Lim R, Walmsley B (1998) Developmental changes in EPSC quantal size and quantal content at a central glutamatergic synapse in rat. J Physiol (Lond) 511:861-869.

Blatchley BJ, Cooper WA, Coleman JR (1987) Development of auditory brainstem response to tone pip stimuli in the rat. Brain Res 429:75-84.

Bollmann JH, Sakmann B, Borst JG (2000) Calcium sensitivity of glutamate release at a calyx-like terminal. Science 289:953-957.

Brenowitz S, Trussell LO (2001) Minimizing synaptic depression by control of release probability. J Neurosci 21:1857-1867.

Brenowitz S, David J, Trussell L (1998) Enhancement of synaptic efficacy by presynaptic $\mathrm{GABA}_{\mathrm{B}}$ receptors. Neuron 20:135-141.

Brew HM, Forsythe ID (1995) Two voltage-dependent K+ conductances with complementary functions in postsynaptic integration at a central auditory synapse. J Neurosci 15:8011-8022.

Chavis P, Westbrook G (2001) Integrins mediate functional pre- and postsynaptic maturation at a hippocampal synapse. Nature 411:317-321.

Christensen BN, Martin AR (1970) Estimates of probability of transmitter release at the mammalian neuromuscular junction. J Physiol (Lond) 210:933-945.

Chuhma N, Ohmori H (1998) Postnatal development of phase-locked high-fidelity transmission in the medial nucleus of the trapezoid body of the rat. J Neurosci 18:512-520.

Dittman JS, Regehr WG (1998) Calcium dependence and recovery kinetics of presynaptic depression at the climbing fiber to Purkinje cell synapse. J Neurosci 18:6147-6162.

Elmqvist D, Quastel D (1965) A quantitative study of end-plate potentials in isolated human muscle. J Physiol (Lond) 178:505-529.

Futai K, Okada M, Matsuyama K, Takahashi T (2001) High-fidelity transmission acquired via a developmental decrease in NMDA receptor expression at an auditory synapse. J Neurosci 21:3342-3349.

Golding NL, Robertson D, Oertel D (1995) Recordings from slices indicate that octopus cells of the cochlear nucleus detect coincident firing of auditory nerve fibers with temporal precision. J Neurosci 15:3138-3153.

Gray L, Rubel EW (1985) Development of absolute thresholds in chickens. J Acoust Soc Am 77:1162-1172.

Iwasaki S, Takahashi T (2001) Developmental regulation of transmitter release at the calyx of Held in rat auditory brainstem. J Physiol (Lond) 534:861-871. 
Jackson H, Parks TN (1982) Functional synapse elimination in the developing avian cochlear nucleus with simultaneous reduction in cochlear nerve axon branching. J Neurosci 2:1736-1743.

Jackson H, Hackett JT, Rubel EW (1982) Organization and development of brain stem auditory nuclei in the chick: ontogeny of postsynaptic responses. J Comp Neurol 210:80-86.

Jhaveri S, Morest DK (1982) Sequential alterations of neuronal architecture in nucleus magnocellularis of the developing chicken: a Golgi study. Neuroscience 7:837-853.

Jones TA, Jones SM (2000) Spontaneous activity in the statoacoustic ganglion of the chicken embryo. J Neurophysiol 83:1452-1468.

Katz LC, Shatz CJ (1996) Synaptic activity and the construction of cortical circuits. Science 274:1133-1138.

Kraushaar U, Jonas P (2000) Efficacy and stability of quantal GABA release at a hippocampal interneuron-principal neuron synapse. J Neurosci 20:5594-5607.

Lawrence JJ, Trussell LO (2000) Long-term specification of AMPA receptor properties after synapse formation. J Neurosci 20:4864-4870.

Lippe WR (1994) Rhythmic spontaneous activity in the developing avian auditory system. J Neurosci 14:1486-1495.

Lu T, Trussell LO (2000) Inhibitory transmission mediated by asynchronous transmitter release. Neuron 26:683-694.

Manley GA, Kaiser A, Brix J, Gleich O (1991) Activity patterns of primary auditory-nerve fibres in chickens: development of fundamental properties. Hear Res 57:1-15.

Matveev V, Wang XJ (2000) Implications of all-or-none synaptic transmission and short-term depression beyond vesicle depletion: a computational study. J Neurosci 20:1575-1588.

Mikaelian D, Ruben RJ (1964) Development of hearing in the normal CBA-J mouse. Acta Otolaryngol 59:451-461.

O’Donovan MJ, Rinzel J (1997) Synaptic depression: a dynamic regulator of synaptic communication with varied functional roles. Trends Neurosci 20:431-433.

Oertel D (1999) The role of timing in the brain stem auditory nuclei of vertebrates. Annu Rev Physiol 61:497-519.

Otis TS, Trussell LO (1996) Inhibition of transmitter release shortens the duration of the excitatory synaptic current at a calyceal synapse. J Neurophysiol 76:3584-3588.

Partin KM, Fleck MW, Mayer ML (1996). AMPA receptor flip/flop mutants affecting deactivation, desensitization, and modulation by cyclothiazide, aniracetam, and thiocyanate. J Neurosci 16:6634-6647.

Raman IM, Trussell LO (1995) The mechanism of alpha-amino-3hydroxy-5-methyl-4-isoxazolepropionate receptor desensitization after removal of glutamate. Biophys J 68:137-146.

Rathouz M, Trussell L (1998) Characterization of outward currents in neurons of the avian nucleus magnocellularis. J Neurophysiol $80: 2824-2835$.
Rebillard G, Rubel EW (1981) Electrophysiological study of the maturation of auditory responses from the inner ear of the chick. Brain Res 229:15-23.

Reyes A, Rubel E, Spain W (1994) Membrane properties underlying the firing of neurons in the avian cochlear nucleus. $J$ Neurosci 14:5352-5364.

Rubel EW, Parks TN (1988) Organization and development of the avian brain-stem auditory system. In: Auditory function (Edelman G, ed), pp 3-92. New York: Wiley.

Sanes DH, Constantine-Paton M (1985) The development of stimulus following in the cochlear nerve and inferior colliculus of the mouse. Brain Res 354:255-267.

Saunders JC, Coles RB, Gates GR (1973) The development of auditory evoked responses in the cochlea and cochlear nuclei of the chick. Brain Res 63:59-74.

Schneggenburger R, Meyer AC, Neher E (1999) Released fraction and total size of a pool of immediately available transmitter quanta at a calyx synapse. Neuron 23:399-409.

Taschenberger H, von Gersdorff H (2000) Fine-tuning an auditory synapse for speed and fidelity: developmental changes in presynaptic waveform, EPSC kinetics, and synaptic plasticity. J Neurosci 20:9162-9173.

Trussell LO (1999) Synaptic mechanisms for coding timing in auditory neurons. Annu Rev Physiol 61:477-496.

Vyklicky Jr L, Patneau DK, Mayer ML (1991) Modulation of excitatory synaptic transmission by drugs that reduce desensitization at AMPA/ kainate receptors. Neuron 7:971-984.

Wang C, Zucker RS (1998) Regulation of synaptic vesicle recycling by calcium and serotonin. Neuron 21:155-167.

Wang LY, Kaczmarek LK (1998) High-frequency firing helps replenish the readily releasable pool of synaptic vesicles. Nature 394:384-388.

Warchol ME, Dallos P (1990) Neural coding in the chick cochlear nucleus. J Comp Physiol [A] 166:721-734.

Weis S, Schneggenburger R, Neher E (1999) Properties of a model of $\mathrm{Ca}(++)$-dependent vesicle pool dynamics and short term synaptic depression. Biophys J 77:2418-2429.

Wu LG, Borst JG (1999) The reduced release probability of releasable vesicles during recovery from short-term synaptic depression. Neuron 23:821-832.

Wu SH, Oertel D (1987) Maturation of synapses and electrical properties of cells in the cochlear nuclei. Hear Res 30:99-110.

Zhang S, Trussell LO (1994a) Voltage clamp analysis of excitatory synaptic transmission in the avian nucleus magnocellularis. J Physiol (Lond) 480:123-136.

Zhang S, Trussell LO (1994b) A characterization of excitatory postsynaptic potentials in the avian nucleus magnocellularis. J Neurophysiol 72:705-718. 